NATIONAL LABORATORY

MANAGED BY UT-BATTELLE

FOR THE DEPARTMENT OF ENERGY

\title{
CHEMICAL COMPATIBILITY ISSUES ASSOCIATED WITH USE OF SiC/SIC IN ADVANCED REACTOR CONCEPTS
}

D. F. Wilson

November 2012

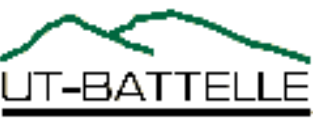




\section{DOCUMENT AVAILABILITY}

Reports produced after January 1, 1996, are generally available free via the U.S. Department of Energy (DOE) Information Bridge.

Web site http://www.osti.gov/bridge

Reports produced before January 1, 1996, may be purchased by members of the public from the following source.

National Technical Information Service

5285 Port Royal Road

Springfield, VA 22161

Telephone 703-605-6000 (1-800-553-6847)

TDD 703-487-4639

Fax 703-605-6900

E-mail info@ntis.fedworld.gov

Web site http://www.ntis.gov/support/ordernowabout.htm

Reports are available to DOE employees, DOE contractors, Energy Technology Data Exchange (ETDE) representatives, and International Nuclear Information System (INIS)

representatives from the following source.

Office of Scientific and Technical Information

P.O. Box 62

Oak Ridge, TN 37831

Telephone 865-576-8401

Fax 865-576-5728

E-mail reports@adonis.osti.gov

Web site http://www.osti.gov/contact.html

This report was prepared as an account of work sponsored by an agency of the United States Government. Neither the United States Government nor any agency thereof, nor any of their employees, makes any warranty, express or implied, or assumes any legal liability or responsibility for the accuracy, completeness, or usefulness of any information, apparatus, product, or process disclosed, or represents that its use would not infringe privately owned rights. Reference herein to any specific commercial product, process, or service by trade name, trademark, manufacturer, or otherwise, does not necessarily constitute or imply its endorsement, recommendation, or favoring by the United States Government or any agency thereof. The views and opinions of authors expressed herein do not necessarily state or reflect those of the United States Government or any agency thereof. 
Materials Science and Technology Division

\section{CHEMICAL COMPATIBILITY ISSUES ASSOCIATED WITH USE OF SiC/SiC IN ADVANCED REACTOR CONCEPTS}

D. F. Wilson

Date Published: November 2012

Prepared for the U.S. Department of Energy Office of Nuclear Energy

Prepared by

OAK RIDGE NATIONAL LABORATORY

Oak Ridge, Tennessee 37831-6285

managed by

UT-Battelle, LLC

for the

U.S. DEPARTMENT OF ENERGY

under contract DE-AC05-00OR22725 



\section{CONTENTS}

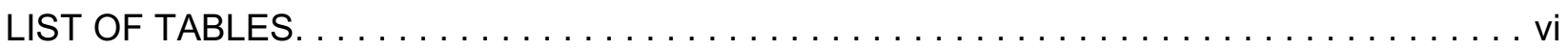

EXECUTIVE SUMMARY.............................. vii

1.0 FHR COMPONENT DESCRIPTION AND OPERATION CONDITIONS. . . . . . . . . 1

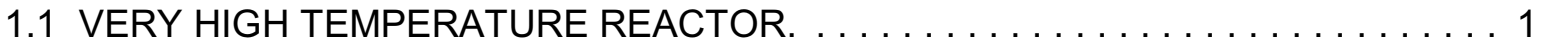

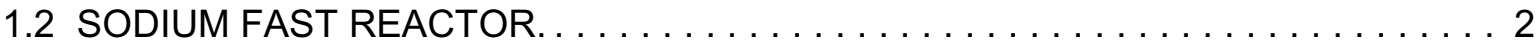

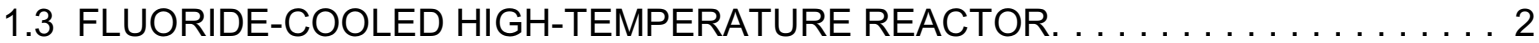

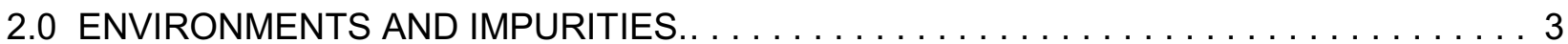

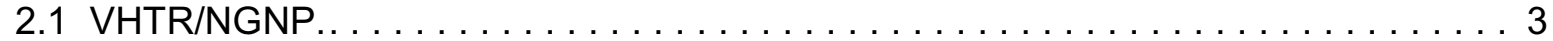

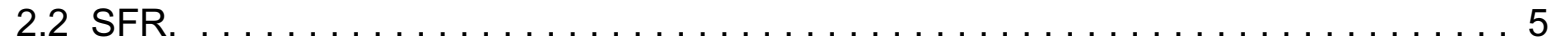

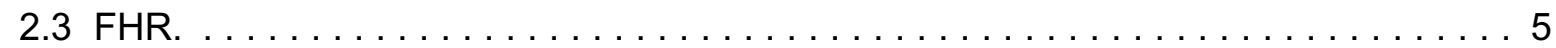

3.0 STRUCTURAL SiC/SiC COMPOSITES..................... 7

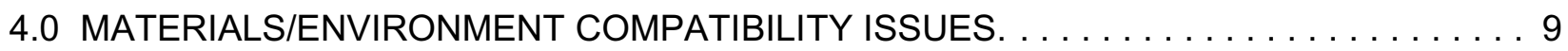

5.0 KNOWLEDGE DEVELOPMENT PLAN OUTLINE $\ldots \ldots \ldots \ldots \ldots \ldots \ldots \ldots \ldots \ldots$

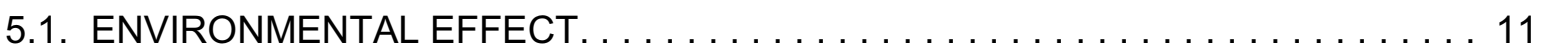

5.2 NEAR TERM TESTING. . . . . . . . . . . . . . . . . . . . . . 13

5.3 COLLABORATION WITH OTHER U.S. MATERIALS DEVELOPMENTS. . . . . . 14

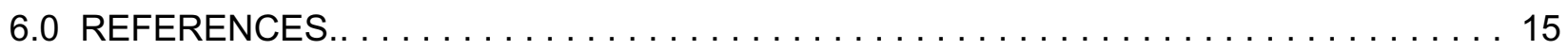




\section{LIST OF TABLES}

Page

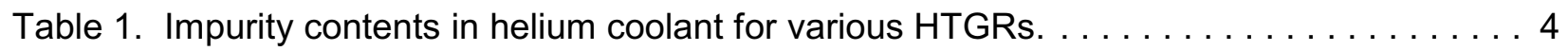

Table 2. Compositions of helium environments (advanced HTGR) used in past tests. . . . . . 5 


\section{EXECUTIVE SUMMARY}

Silicon carbide/silicon carbide ( $\mathrm{SiC} / \mathrm{SiC}$ ) composites are of interest for components that will experience high radiation fields in the High Temperature Gas Cooled Reactor (HTGR), the Very High Temperature Reactor (VHTR), the Sodium Fast Reactor (SFR), or the Fluoride-cooled High-temperature Reactor (FHR). In all of the reactor systems considered, reactions of SiC/SiC composites with the constituents of the coolant determine suitability of materials of construction.

The material of interest is nuclear grade $\mathrm{SiC} / \mathrm{SiC}$ composites, which consist of a SiC matrix [high-purity, chemical vapor deposition (CVD) SiC or liquid phase-sintered $\mathrm{SiC}$ that is crystalline beta-phase SiC containing small amounts of alumina-yttria impurity], a pyrolytic carbon interphase, and somewhat impure yet crystalline beta-phase SiC fibers. The interphase and fiber components may or may not be exposed, at least initially, to the reactor coolant. The chemical compatibility of $\mathrm{SiC} / \mathrm{SiC}$ composites in the three reactor environments is highly dependent on thermodynamic stability with the pure coolant, and on reactions with impurities present in the environment including any ingress of oxygen and moisture. In general, there is a dearth of information on the performance of $\mathrm{SiC}$ in these environments. While there is little to no excess $\mathrm{Si}$ present in the new $\mathrm{SiC} / \mathrm{SiC}$ composites, the reaction of $\mathrm{Si}$ with $\mathrm{O}_{2}$ cannot be ignored, especially for the $\mathrm{FHR}$, in which environment the product, $\mathrm{SiO}_{2}$, can be readily removed by the fluoride salt. In all systems, reaction of the carbon interphase layer with oxygen is possible especially under abnormal conditions such as loss of coolant (resulting in increased temperature), and air and/ or steam ingress. A global outline of an approach to resolving $\mathrm{SiC} / \mathrm{SiC}$ chemical compatibility concerns with the environments of the three reactors is presented along with ideas to quickly determine the baseline compatibility performance of $\mathrm{SiC} / \mathrm{SiC}$ 



\subsection{FHR COMPONENT DESCRIPTION AND OPERATION CONDITIONS}

Silicon carbide/silicon carbide ( $\mathrm{SiC} / \mathrm{SiC})$ composites are of interest for components that will experience high radiation fields in the High Temperature Gas Cooled Reactor (HTGR), the Very High Temperature Reactor (VHTR), the Sodium Fast Reactor (SFR), and the Fluoride-cooled High-temperature Reactor (FHR). While all designs are conceived as being capable of generating electrical power, the SFR is focused on management of high-level waste, and the VHTR and FSR are focused on electrical power generation and, at least at the higher operating temperatures, hydrogen production. Abbreviated descriptions of these reactor concepts are presented in this section of the report.

\subsection{VERY HIGH TEMPERATURE REACTOR}

As proposed, the U.S. Department of Energy (DOE), Next Generation Nuclear Plant (NGNP) Project is envisioned as a Very High Temperature Reactor (VHTR). The present designs are either a graphite-moderated, helium-cooled, prismatic core or a pebble-bed thermal neutron spectrum reactor with an average reactor outlet temperature, originally proposed to be at least $1000^{\circ} \mathrm{C}$ but, due mainly to materials limitations, currently planned to be at least $800^{\circ} \mathrm{C}$. The NGNP, which has a design service life of 60 years, will employ very high burn-up, low-enriched uranium, TRISO-Coated fuel in a once-through fuel cycle. ${ }^{1}$ Similarly, a study by General Atomics based on their modular helium reactor (MHR) with prismatic core blocks and reactor

power of $600 \mathrm{MWth},{ }^{2}$ initially assumed a reactor outlet temperature of $950^{\circ} \mathrm{C}$ but later included four different outlet temperatures; $687^{\circ} \mathrm{C}, 750^{\circ} \mathrm{C}, 800^{\circ} \mathrm{C}$, and $950^{\circ} \mathrm{C}$, due to serious concerns about the unavailability of code-qualified high temperature materials. 


\subsection{SODIUM FAST REACTOR}

The Sodium-Cooled Fast Reactor (SFR) system is conceived as a fast-spectrum, sodium-cooled reactor with a closed fuel cycle that allows for efficient management of high-level wastes and, in particular, management of plutonium and other actinides. Three variants of the reactor are proposed. The first variant is a large size (600 to 1,500 MWe) loop-type sodium-cooled reactor using mixed uranium-plutonium oxide fuel; the second variant is an intermediate size ( 300 to $600 \mathrm{MWe}$ ) pool-type reactor; and the third variant is a small size (50 to 150MWe) modular-type sodium-cooled reactor that would use uranium-plutonium-minor-actinide-zirconium metal alloy fuel. The outlet temperature is approximately $550^{\circ} \mathrm{C}$ for all of the three variants. ${ }^{3}$

\subsection{FLUORIDE-COOLED HIGH-TEMPERATURE REACTOR}

Fluoride-cooled High-temperature Reactors (FHRs) combine the use of liquid fluoride salt coolants, pool-type cores and vessel configurations, and coated particle fuels similar to high temperature gas-cooled reactors. There are two proposed variants: a $1200 \mathrm{MWe}$ Advanced High Temperature Reactor (AHTR) that uses prismatic fuel elements and the $410 \mathrm{MWe}$ Pebble Bed Advanced High Temperature Reactor (PB-AHTR). ${ }^{4}$ These reactors employ liquid-fluoride-salt coolants, tri-isotropic (TRISO)-coated particle fuels and graphite moderator materials. The FHRs operate with primary system pressures near atmospheric pressure and at coolant temperatures in the range of $600^{\circ} \mathrm{C}$ to $\sim 1000^{\circ} \mathrm{C}$. The use of liquid fluoride salt coolants offer two potential advantages: smaller equipment size, because of the higher volumetric heat capacity of the salts, and the absence of chemical exothermal reactions between the reactor intermediate loop coolant and power cycle coolant. 


\subsection{ENVIRONMENTS AND IMPURITIES}

In all of the reactor systems considered, reactions of $\mathrm{SiC} / \mathrm{SiC}$ composites with the constituents of the coolant determine suitability of materials of construction. In all cases, ingress of air/moisture plays a significant role in materials performance. Brief descriptions of the various environments are presented in this section.

\subsection{VHTR/NGNP}

The interactions between structural materials in the helium atmospheres associated with gas-cooled reactors have been the subject of numerous investigations (see Kimball ${ }^{5}$ ). The results of these studies conducted by various organizations in the United States, Germany, England, Norway, Japan, and other places have demonstrated the importance of small changes in impurity levels, high temperatures and high gas flow rates. Metallic materials can be carburized or decarburized, and oxidized internally or at the surface. These corrosion reactions, depending on their rate, can substantially affect long-term mechanical properties such as fracture toughness, fatigue behavior, crack-growth rate, etc. Hence, the helium environment has targeted ranges of operating oxygen and carbon potentials. However, there is a dearth of open literature work on the behavior of $\mathrm{SiC} / \mathrm{SiC}$ in these environments.

AREVA evaluated the baseline operating conditions envelope for the prismatic core high temperature gas cooled reactor specified in their pre-conceptual NGNP design studies. ${ }^{6}$ The assumed reactor power level and the core inlet/outlet temperatures are $565 \mathrm{MW}$ th and $500 / 900^{\circ} \mathrm{C}$ for the VHTR baseline and $600 \mathrm{MW}$ th and $350 / 750^{\circ} \mathrm{C}$ for the HTGR baseline. The report anticipates the use a helium purification system similar to those employed in prior HTGR's and resulting impurity levels similar to those presented in Table 1. The report also 
points out that air and water ingress during various abnormal events can degrade reactor materials, including graphite and ceramic composites.

Table 1. Impurity contents in helium coolant for various HTGRs ${ }^{6}$

\begin{tabular}{lccccccc}
\hline \multicolumn{1}{c}{ Reactor } & $\mathbf{H}_{2}(\mathbf{p p m})$ & $\begin{array}{c}\mathrm{H}_{2} \mathbf{O} \\
(\mathbf{p p m})\end{array}$ & $\begin{array}{c}\mathbf{C O} \\
(\mathbf{p p m})\end{array}$ & $\begin{array}{c}\mathrm{CO}_{2} \\
(\mathbf{p p m})\end{array}$ & $\begin{array}{c}\mathrm{CH}_{4} \\
(\mathbf{p p m})\end{array}$ & $\mathbf{N}_{2}(\mathbf{p p m})$ & $\mathbf{O}_{2}(\mathbf{p p m})$ \\
\hline Dragon & 0.1 & 0.1 & 0.05 & 0.02 & 0.01 & 0.05 & 0.1 \\
Peach Bottom & 0.5 & 0.5 & 0.5 & $<0.05$ & 1 & 0.5 & - \\
Fort St. Vrain & 1 & 1 & 3 & 1 & 0.1 & & - \\
AVR & 0.15 & 0.15 & 45 & 0.25 & 1 & 22 & - \\
THTR & $<0.01$ & $<0.01$ & 0.4 & 0.2 & 0.1 & 0.1 & - \\
\hline
\end{tabular}

AVR: Arbeitsgemeinschaft Versuchsreaktor

THTR: Thorium High Temperature Reactor

Table 2 presents the typical simulated advanced High-Temperature Gas Reactor (HTGR) helium chemistries used in various previous test programs. Because of the low partial pressures of the impurities, the oxidation/carburization potentials at the material surface of a gas mixture are established by the kinetics of the individual impurity catalyzed reactions at the surface. The main impurities are $\mathrm{H}_{2}, \mathrm{H}_{2} \mathrm{O}, \mathrm{CO}$ and $\mathrm{CH}_{4}$. The hot graphite core is considered as reacting with all free $\mathrm{O}_{2}$ and much of the $\mathrm{CO}_{2}$ to form $\mathrm{CO}$, and with $\mathrm{H}_{2} \mathrm{O}$ to form $\mathrm{CO}$ and $\mathrm{H}_{2}$. In addition, in cooler regions of the core, $\mathrm{H}_{2}$ reacts with the graphite via radiolysis to produce $\mathrm{CH}_{4}$. The overall chemical stability of the proposed helium environment that will be representative of the NGNP must be evaluated in order to ensure that testing is performed in environments that have consistent chemical potentials for the components as for example, the control rod of pebble-bed core HTGRs and VHTRs, for which ceramic and SiC/SiC composites have been proposed. ${ }^{7}$ In addition, the corrosion of $\mathrm{SiC} / \mathrm{SiC}$ must be evaluated to establish baseline data where it does not exist. Therefore, testing of both the helium environment to be used for mechanical properties and general corrosion evaluations of the candidate $\mathrm{SiC} / \mathrm{SiC}$ composites 
to establish their overall compatibility with that environment must be performed at temperatures up to at least $50^{\circ} \mathrm{C}$ above the proposed operating temperature for the various components.

Table 2. Compositions of helium environments (advanced HTGR) used in past tests ${ }^{5}$

\begin{tabular}{|c|c|c|c|c|c|c|c|}
\hline Pogram & 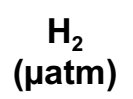 & $\begin{array}{c}\mathrm{H}_{2} \mathrm{O} \\
(\mu \mathrm{atm})\end{array}$ & 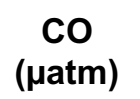 & 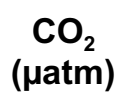 & 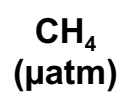 & 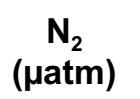 & $\begin{array}{l}\text { He (atm } \\
\text { absolute) }\end{array}$ \\
\hline NPH/HHT & 500 & 1.5 & 40 & & 50 & $5-10$ & 2 \\
\hline PNP & 500 & 1.5 & 15 & & 20 & $<5$ & 2 \\
\hline HTR & 500 & 1 & 50 & & 20 & & 2 \\
\hline AGCNR & 400 & 2 & 40 & 0.2 & 20 & $<20$ & 2 \\
\hline \multicolumn{8}{|c|}{$\begin{array}{l}\text { NPH: Nuclear Process heat } \\
\text { HHT: High-temperature Helium Turbine Systems } \\
\text { PNP: Prototype Nuclear Process Heat } \\
\text { HTR: High Temperature Reactor } \\
\text { AGCNR: Advanced Gas Cooled Nuclear Reactor }\end{array}$} \\
\hline
\end{tabular}

\subsection{SFR}

The typical impurities in "commercially pure" (min 99.95\%) sodium have been reviewed. ${ }^{8,9}$ Typically, impurities are of the order of a combined total of $500 \mathrm{ppm}$ for calcium, iron, lead, magnesium, silicon, sulfur, and zinc; about 300 ppm for potassium; and, unfortunately, unknown levels for oxygen, carbon and nitrogen. A lack of certainty for the oxygen level (100 ppm has been suggested but not analytically confirmed) is particularly disconcerting, as oxygen plays an important role in the compatibility behavior of materials in sodium. Again, there is a dearth of information of $\mathrm{SiC} / \mathrm{SiC}$ compatibility with sodium.

\subsection{FHR}

FHR will employ $67 \mathrm{LiF}-33 \mathrm{BeF}_{2}(\mathrm{FLiBe})$ as its primary coolant and either $46.5 \mathrm{LiF}-11.5 \mathrm{NaF}-42 \mathrm{KF}$ (FLiNaK) or $58 \mathrm{KF}-42 \mathrm{ZrF}_{4}$ as its intermediate and Direct Reactor Auxiliary Cooling System 
(DRACS) coolants. Thermodynamic stability of the material constituents versus fluoride salt constituents is quite important to minimize corrosion. Chemically available fluorine atoms typically arise due to electronegative impurities within the otherwise strongly ionically bound fluoride melt. Temperature differences within a single thermal loop cause gradients in the chemical activities of the loop constituents and can result in dissolution of a constituent of a component of material in one region of the system with subsequent deposition in other portions of the system. The degree of attack will depend on the thermodynamic driving force of the reaction, the dissolution and deposition kinetics, and the temperature distribution, as well as the loop hydraulic properties.

A continuous flowing cover gas (mostly helium) will be employed over the primary salt in the reactor vessel to assist in sweeping tritium (which will be produced via neutron transmutation of the salt) and ingress gases (especially oxygen and moisture) away from the liquid salt coolants to cleanup systems. Some oxygen will unavoidably be present within the containment and will leak into the gas volume above the coolant salt. This oxygen can react with the $\mathrm{SiC} / \mathrm{SiC}$ composites and lead to degradation of properties. Very little information is available on the performance of $\mathrm{SiC} / \mathrm{SiC}$ composites in fluoride salts, and the behavior of pure silicon carbide in fluoride salts has to be inferred from its behavior in other environments. ${ }^{10}$ The complexity of the inferences increases when one considers $\mathrm{SiC} / \mathrm{SiC}$ composites rather than pure $\mathrm{SiC}$, but it is clear that oxygen will play a significant role in the compatibility of $\mathrm{SiC} / \mathrm{SiC}$ composites in fluoride salts. 


\subsection{STRUCTURAL SiC/SiC COMPOSITES}

The material of interest is nuclear grade $\mathrm{SiC} / \mathrm{SiC}$ composites, which consist of a $\mathrm{SiC}$ matrix (high purity CVD SiC or liquid phase-sintered $\mathrm{SiC}$ that is crystalline beta-phase $\mathrm{SiC}$ containing small amounts of alumina-yttria impurity), a pyrolytic carbon interphase, and somewhat impure yet crystalline beta-phase SiC fibers. The interphase and fiber components may or may not be exposed, at least initially, to the reactor coolant.

Generation III SiC fibers, Type-S Hi-Nicalon fiber, and Tyranno-SA3 (sintered SiC fibers with additions of alumina) have near-stoichiometric composition and high degree of crystallization. These fibers are considered adequate mechanical properties and radiation resistance for nuclear services. Tyranno-SA3 offers a significantly higher upper temperature limit but higher thermal creep rate at lower temperatures. ${ }^{7}$

A composite with Hi-Nicalon ${ }^{\mathrm{TM}}$ Type-S reinforcement, chemical vapor infiltrated (CVI) SiC matrix, and the engineered interphase (interface layer between the fiber and the matrix) made of pyrolytic carbon and silicon carbide, has been defined as the reference $\mathrm{SiC} / \mathrm{SiC}$ composite material in the U.S. DOE NGNP Composite R\&D program (FY-05 to 08). ${ }^{7}$ The Hi-Nicalon Type-S fiber was chosen solely on the fact that the U.S. composite venders had more experience with that fiber than Tyranno-SA3 fiber. The interphase consists of alternating thin layers of pyrolytic carbon and silicon carbide and offers the potential benefit of enhanced oxidation resistance; and the mechanical properties and radiation resistance of composites with thin pyrolytic carbon monolayer interphase are equivalent. ${ }^{7}$ 
Various processing routes exist for the manufacture of these composites including chemical vapor infiltration (CVI) and transient eutectic-phase process (NITE), which produce highly crystalline and stoichiometric SiC matrices. The CVI process results in a limit on densification. The NITE process does require the use of sintering agents, alumina, yttria, and silica, to lower the eutectic temperature enough for survival of the fibers and the engineered interphases. Control of the quality and quantity of the residual oxide phases resulting from the sintering additives is important in order to maintain composite performance. ${ }^{7}$ 


\subsection{MATERIALS/ENVIRONMENT COMPATIBILITY ISSUES}

As presented earlier, the chemical compatibility of $\mathrm{SiC} / \mathrm{SiC}$ composites in the three reactor environments is highly dependent on thermodynamic stability with the pure environment, and on reactions with impurities present in the environment including any ingress of oxygen and moisture. In general, there is a dearth of information on the performance of $\mathrm{SiC}$ in these in these environments. While there is little to no excess Si present in the new SiC/SiC composites, the reaction of $\mathrm{Si}$ with $\mathrm{O}_{2}$ cannot be ignored especially for the FHR environment, in which the product, $\mathrm{SiO}_{2}$, can be readily removed by the fluoride salt. In all systems, reaction of the carbon interphase layer with oxygen is possible especially under abnormal conditions such as loss of coolant (resulting in increased temperature), and ingress of air and/or steam.

The reaction of $\mathrm{SiC}$ with $\mathrm{O}_{2}$ has received some attention. The work of Gulbransen and Jansson ${ }^{11}$ has demonstrated a critical oxygen pressure for the transition from active formation of silicon oxide and carbon monoxide with linear oxidation kinetics at low oxygen potentials to passive behavior, resulting from the formation of self-healing silicon dioxide with parabolic oxidation kinetics at high oxygen potentials. Antila and Warburton ${ }^{12}$ demonstrated the active to passive oxidation of beta-silicon carbide occurs below $10^{-6}$ atm at $1000^{\circ} \mathrm{C}$. Ervin ${ }^{13}$ has presented eight possible reactions between silicon carbide and oxygen to produce silicon dioxide, silicon oxide, and silicon that have negative free energy changes within the temperature range of interest and are, therefore, thermodynamically possible. Hence, in all reactor systems, the partial pressure of oxygen is important to materials performance. Further, even assuming that silicon carbide is thermodynamically stable in the molten fluoride salt and in molten sodium, control of the oxygen partially pressure is critical to long-term performance of silicon carbide. 
Research performed by Song et al., ${ }^{14}$ and McKee and Chatterji ${ }^{15}$ leads to the conclusion that in the presence of molten salts, corrosion of $\mathrm{SiC}$ can occur at high oxygen partial pressures in the presence of basic salt melts and at very low oxygen partial pressures regardless of the basicity/acidity of the salt melts, and passivation can occur at high oxygen partial pressures and in the presence of acidic or neutral salt melts. This effect for silicon carbide with respect to basic salts is consistent with the conclusions presented for metallic materials in ORNL/TM-2006/140 ${ }^{16}$, which concludes that FLiNaK, a strongly basic salt, supports a higher degree of corrosion as compared to the other fluoride salts evaluated.

Unfortunately, a similar analysis for $\mathrm{SiC}$ in sodium could not be performed, even by analogy, and basic data need to be developed. 


\subsection{KNOWLEDGE DEVELOPMENT PLAN OUTLINE}

The environment expected for the Next Generation Nuclear Plant reactor will be very challenging for the structural materials. The sustained operating temperature may reach $1000^{\circ} \mathrm{C}$ in a helium atmosphere with a pressure of $7.5 \mathrm{MPa}$ and flow velocities on the order of $40 \mathrm{~m} / \mathrm{s}$. A pure helium atmosphere would not cause environmental degradation of high-temperature materials such as $\mathrm{SiC} / \mathrm{SiC}$ composites, but the helium could be contaminated with gaseous impurities such as $\mathrm{CO}, \mathrm{CO}_{2}, \mathrm{CH}_{4}, \mathrm{H}_{2}, \mathrm{H}_{2} \mathrm{O}$, and $\mathrm{O}_{2}$. A slightly oxidizing environment needed to maintain a thin protective $\mathrm{Cr}$ or Al oxide on conventional high-temperature alloys may be quite aggressive towards $\mathrm{SiC} / \mathrm{SiC}$ composites. High-velocity flowing gases may also contain particulates from abrasion of the graphite or other materials in the system. A particulate-laden high velocity gas also raises the potential issue of particle erosion of some components. Also, oxygen, moisture, and other oxidants can lead to chemical reactions of the environments associated with the SFR and FHR with SiC/SiC.

\subsection{ENVIRONMENTAL EFFECT}

A R\&D program for environmental effects on ceramic composite materials must be implemented in order to determine the long term stability of these materials in the three reactor environments.

- Stability determination in impure helium, molten fluoride salt, and sodium:

Thermodynamic modeling of the environment with respect to $\mathrm{SiC} / \mathrm{SiC}$ must be undertaken to map the stability regime for the various reactors and determine which are common regimes with those required for the metallic structures.

Based on the theoretical study, experimental programs will be developed for addressing critical compatibility issues. 
- $\quad$ Long term exposure to impure helium, molten fluoride salt, and sodium:

Oxidation is known to degrade various properties of carbon-based materials especially at elevated temperatures. The oxidation behavior is strongly affected by material attributes such as porosity, molecular structure and/or degree of graphitization. Both normal and off-normal environments must be considered.

$\mathrm{SiC} / \mathrm{SiC}$ composites, can develop microcracks, suffer enhanced oxidation of the carbon interphase. Long term evaluation of $\mathrm{SiC} / \mathrm{SiC}$ composites with defined microcracking must be performed. Both normal and off-normal environments must be considered.

- $\quad$ Testing in flowing systems:

While testing in impure helium is by necessity performed in flowing loops, either once through or preferably recirculating, testing in fluoride salts and in sodium can be initiated in static capsule tests.

These static tests allow for determination of reaction rates for the various forms of $\mathrm{SiC} / \mathrm{SiC}$ compatibility with fluoride and sodium with and without additives.

Flow loop tests will allow for further evaluations of materials performance in thermal gradients.

- Development of life prediction models:

These various studies will allow for the development of life prediction models for the degradation of the materials. These models will be crucial in predicting a 60 -year life without 60 years of testing. 


\subsection{NEAR TERM TESTING}

Thermodynamic stability assessment and testing should be implemented to evaluate the performance of SiC/SiC composites in both sodium and fluoride salt. These tests should incorporate static capsule tests and include two to three types of $\mathrm{SiC} / \mathrm{SiC}$ composites. These tests will establish the baseline performance for SiC/SiC.

Work needs to be performed to create a sound thermodynamic foundation for the evaluation of silicon carbide in molten fluoride salts with respect to the basicity/acidity of the salt and low partial oxygen pressures that are to be expected in reactor systems. A similar evaluation is needed for silicon carbide composites in sodium.

As the techniques for purifying the fluoride salts are well understood and the FHR will employ purified salts and have on-line cleanup capabilities, testing with $\mathrm{SiC} / \mathrm{SiC}$ should be performed with purified salt. Temperatures of $600,700,800,900$ and $1000^{\circ} \mathrm{C}$ should be employed. The test matrix should incorporate at least three materials, five exposure temperatures, and four exposure durations with replicates.

As the techniques for purifying sodium are in the development stage and analytical techniques for evaluating the impurity content of sodium are lacking, two purity levels are proposed: as received from the vendor (as received oxygen), and as-purified in the laboratory with existing techniques (low oxygen). Test temperatures of 500,600 , and 700 should be employed. The test matrix should include at least three materials, three exposure temperatures, and two oxygen levels at four exposure durations with replicates. 


\subsection{COLLABORATION WITH OTHER U.S. MATERIALS DEVELOPMENTS}

To ensure that evaluations of $\mathrm{SiC} / \mathrm{SiC}$ composites are not duplicated, a dialogue and collaboration between the NGNP materials effort, other Generation IV programs, and other significant U.S. materials efforts are appropriate. Materials development and qualification activities are underway on several other major DOE programs in the United States. For example, the DOE Office of Fossil Energy's materials research programs includes research on developing high-temperature alloys and refractories and advanced carbon products, and the Fusion Materials Development subprogram evaluates materials for their highly challenging irradiation, temperature, and chemical environments. 


\subsection{REFERENCES}

1. G. O. Hayner et al., Next Generation Nuclear Plant Materials Selection and Qualification Program Plan, INEEL/ext-03-01128 Revision 0, November 7, 2003, Idaho National Engineering and Environmental Laboratory, Idaho Falls, Idaho.

2. R. Vollman, NGNP Composites R\&D Technical Issues Study, 911125, Revision 0. 2008, General Atomics, San Diego.

3. http://www.gen-4.org/Technology/systems/sfr.htm

4. http://www.gen-4.org/Technology/systems/msr.htm

5. O. F. Kimball and D. E. Plumblee, Gas/Metal Interaction Studies in Simulated HTGR Helium, HTGR -85-064, General Electric Company, Schenectady, New York, June 1985.

6. E. Barringer, NGNP Composites R\&D Technical Issues Study. 2008, AREVA Federal Services LLC.

7. Yutai Katoh, Lance L. Snead, Timothy D. Burchell, William E. Windes, Composite Technology Development Plan, ORNL/TM-2009/185, Revision 3, Oak Ridge National Laboratory, June 2010.

8. S. J. Pawel, "Compatibility Assessment of HT-UPS, NF-616, and 316L Stainless Steel in Sodium Using Capsules and a Thermal Convection Loop," ORNL/TM-2010/187, Oak Ridge National Laboratory, September 2010

9. S. J. Pawel, "Compatibility Assessment of Advanced Alloys in Sodium," ORNL/TM2011/329, Oak Ridge National Laboratory, September 2011

10. Y. Katoh, D. F. Wilson, and C. W. Forsberg, "Assessment of Silicon Carbide Composities for Advanced Salt-Cooled Reactors, ORNL/TM-2007/168, Oak Ridge National Laboratory, September 2007.

11. E.A. Gulbransen, S.A. Jansson, The High-Temperature Oxidation, Reduction, and Volatilization Reactions of Silicon and Silicon Carbide, Oxidation of Metals 4 (1972) 181-201.

12. J.E. Antill, J.B. Warburton, Active to Passive Transition in the Oxidation of SiC, Corrosion Science 11 (1971) 337-342.

13. G.J. Ervin, Oxidation Behavior of Silicon Carbide, J. Am. Ceram. Soc. 41 (1958) 347- 352.

14. D.Y. Song, S. Kitaoka, H. Kawamoto, Hot Corrosion of Chemical Vapour Deposited SiC and $\mathrm{Si}_{3} \mathrm{~N}_{4}$ in Molten $\mathrm{Na}_{2} \mathrm{SO}_{4}$ Salt, J. Mater. Sci. Let. 33 (1998) 1031-1036.

15. D.W. McKee, D. Chatterji, Corrosion of Silicon Carbide in Gases and Alkaline Melts, J. Am. Ceram. Soc. 59 (1976) 441-444. 
16. D.T. Ingersoll, C.W. Forsberg, P.E. MacDonald, Trade Studies on the Liquid-Salt-Cooled Very High-Temperature Reactor: Fiscal Year 2006 Progress Report, ORNL/TM-2006/140, Oak Ridge National Laboratory, Oak Ridge, Tennessee, 2006. 
